\title{
EXCITABILITY OF THE MEMBRANE OF LUMBER MOTOR NEURONS AND NATURAL SLEEP IN THE CAT
}

\author{
Kisou Kubota AND Yoshiaki KIDOKoRo* \\ Department of Neurophysiology, Institute of Brain Researeh, \\ University of Tokyo, Bunkyo-ku, Tokyo, Japan
}

Amplitude of the monosynaptic reflex is smaller during so-called activated sleep than during slow wave sleep in the cat spinal cord with or without the reflex control through the fusimotor loop ${ }^{7,8,10)}$. A question may arise as to whether any inhibitory mechanisms, pre- and post-synaptic, are operating during the former state. Intracellular recording of the motor neuron in the chronic state would give a crucial answer to this question. This seemed technically infeasible. However, as a substitute, the excitability of the motoneuronal membrane and the primary afferent nerve terminal may be tested by the local stimulation of the spinal cord. In a preliminary study, size of the antidromic focal potential during the two sleep states was studied and its definite change was not revealed ${ }^{17}$.

It is attempted in this paper to observe the excitability change of the motor neuron at a cellular level. A method was used to stimulate the cord so that a limited number of lumbar motor neurons could be excited directly and to record from the hindlimb muscles the evoked single motor unit activities. It will be shown that during the activated sleep the motoneuronal membrane becomes less excitable. Preliminary reports have appeared ${ }^{11,17}$.

\section{METHODS}

Eight adult cats were used. Recording electrodes were implanted aseptically in the skull for EEG, neck muscle for EMG and sciatic nerve10).

For the cord stimulation one or two copper wires ( $90 \mu$ in diam.) covered with a polyurethane film of $15 \mu$ thick except the cut end were thrusted blindly into the ventral part of the spinal cord at the L5-Sl level in a dorso-ventral direction through a punctured hole of the pia. They were fixed by stitching to the dorsal surface of the pia at the more caudal level. As a reference for both stimulation and recording, a polyurethane-coated copper wire $(150 \mu$ in diam.) was thrusted into the dorsal part of the cord at the $\mathrm{S} 2$ level. Its tip was exposed for $1-2 \mathrm{~mm}$. Dorsal roots were cut

Received for publication, November 7, 1965

* 久保田 競, 城所良明 
bilaterally from L5 to S2. This procedure helped to reduce body movements. After the electrodes were implanted, the dura mater was tightly sutured by the threads used for ophthalmological surgery (Elp eyeless needles, Toyohara Co., Tokyo). Experiments were done for 1-4 days after the implantation. Activities of flexors of the ankle and knee joints (tibialis anterior, extensor digitorum longus and biceps femoris) and ankle and knee extensors (soleus, gastrocnemius, probably plantaris, and quadriceps) were evoked by the cord stimulation and were recorded by two syringe needles (diam. $1 \mathrm{~mm}$ ) insulated with polyurethane except the tip and separated by $1-3 \mathrm{~mm}$ from each other. As it was not always possible to identify the name of ankle muscles, they were simply classified as an ankle extensors or ankle flexors. In most of the cats the knee flexors and extensors were denervated.

In the chronic state an appropriate single shock to the cord $(0.1-0.3 \mathrm{msec}$, less than $9 \mathrm{~V}$; either anodally or cathodally) elicited a 'single' motor unit activity of polyphasic shape in all-or-none manner. To assess the direct excitation of the motor neuron by the cord stimulation, the laminectomy was performed under pentobarbital anesthesia after the chronic experiment, and the ventral root (L6, L7, or S1) was mounted for stimulation at the cord entry. The shortest latency of a given muscle activity thereby induced was compared with the latency of the 'single' motor unit which had been obtained by the cord stimulation in the chronic state. When the former was shorter than the latter by less than $0.4 \mathrm{msec}$, the motor unit activity was considered as resulted from the direct excitation of the motor neuron. The value of $0.4 \mathrm{msec}$ will not leave a doubt that a single motor unit is excited transsynaptically (Cf. 16). Alternatively the following measurements could be done in the chronic state. Both the EMG mass response and the antidromic field potential of motor neurons were produced by supramaximal stimulation of the sciatic nerve. When sum of the both responses was shorter by less than $0.4 \mathrm{msec}$ than the latency of the single motor unit by the cord stimulation, the single unit was similarly considered as directly excited.

The same single motor unit activity could be recorded for several hours without any distortion of the potential shape.

Intensities of the cord stimulation to evoke the same motor unit were compared between the slow wave sleep and the following activated sleep. The threshold voltages were determined in the slow wave sleep state. It is represented by the arithmetic means between the highest voltage evoking no motor unit activity by successive 10 trials of approximately 1 cps stimulation and the lowest voltage evoking 10 responses to the same repetitive stimulation. The threshold change during the activated sleep was studied. Although stimulus intensity is not represented in terms of the current, it was always monitored on the oscilloscopic screen as the voltage drop across the small resistor $(1 \mathrm{~K}, 100$, or $50 \Omega$ ) which was inserted in series with the output of the ISU of the stimulator (NIHON KOHDEN MSE 3, output impedance of the ISU was less than $400 \Omega$ ). This recording was used to confirm that the threshold increase during activated sleep to be described, is at least in part, not due to the impedance increase of the cord tissue as a whole between two intraspinal electrodes.

The experiment was completed by passing d.c. current between the two cord electrodes for checking the electrode position. Then, the cord was fixed by $9 \%$ formaline and stained with Kluver-Barerra method. An example of the stained spinal cord is illustrated in Fig. 2.

Recording equipment and experimental environment for the animal were the same as previously described ${ }^{10)}$. 


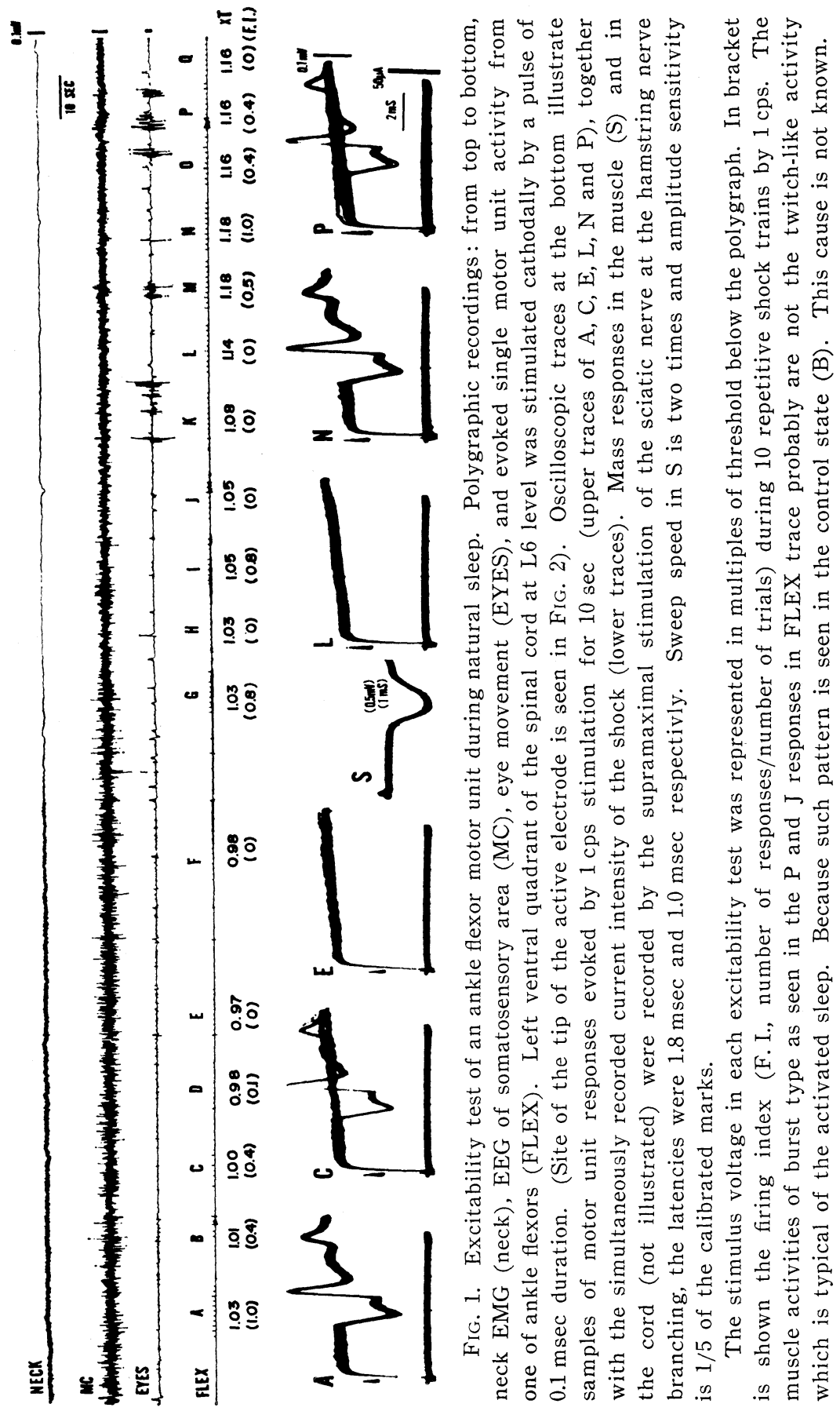




\section{RESULTS}

FIG. 1 illustrates, together with polygraphic recordings of neck EMG, EEG and eye movement, an example of threshold changes of the single motor unit of an ankle flexor elicited by the cord stimulation during a transition from the slow wave sleep to the activated sleep. The EMG unit responses were recorded on the ink-writer in the fourth trace of the polygraph. Some of them are shown in the bottom $(\mathrm{A}, \mathrm{C}, \mathrm{E}, \mathrm{L}, \mathrm{N}, \mathrm{P})$. This unit responded with $3.1 \mathrm{msec}$ latency from the cord and satisfied the criteria of the directly excited activity (Methods). Shocks of varied intensity were given and the firing index (F.I.) of the motor unit was calculated from 10 responses evoked by $1 \mathrm{cps}$ stimulation for $10 \mathrm{sec}$. During the slow wave sleep, as seen to the left of FIG. 1, shocks were given in decreasing order of intensity. The unit was

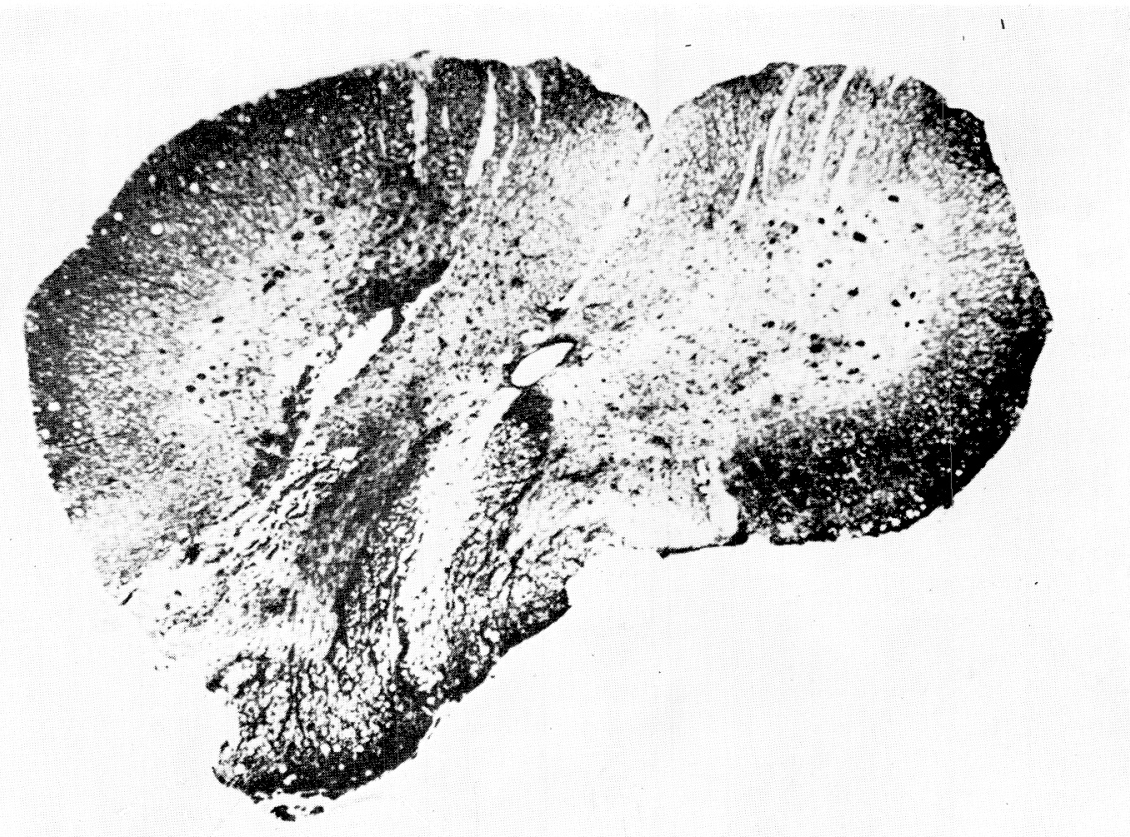

FIG. 2. Spinal cord section to show the electrode position used to evoke the response illustrated in FIG. 1. Tip locates at the medial portion of the left motor neuron pool (L6). Extreme distortion of the implanted side of the cord is due to the inadequate suturing of the dura during the preliminary operation.

always evoked in $\mathrm{A}$ and was not at all in $\mathrm{E}$. In $\mathrm{B}, \mathrm{C}$, and $\mathrm{D}$, some of shocks failed to evoke the response. From the voltages in $\mathrm{A}$ and $\mathrm{E}$ the defined threshold was calculated as $3.32 \mathrm{~V}$, which is approximately identical with the voltage used in C. Numbers shown below the polygraph are the shock intensities relative to the threshold of the slow wave sleep state. Numbers in 

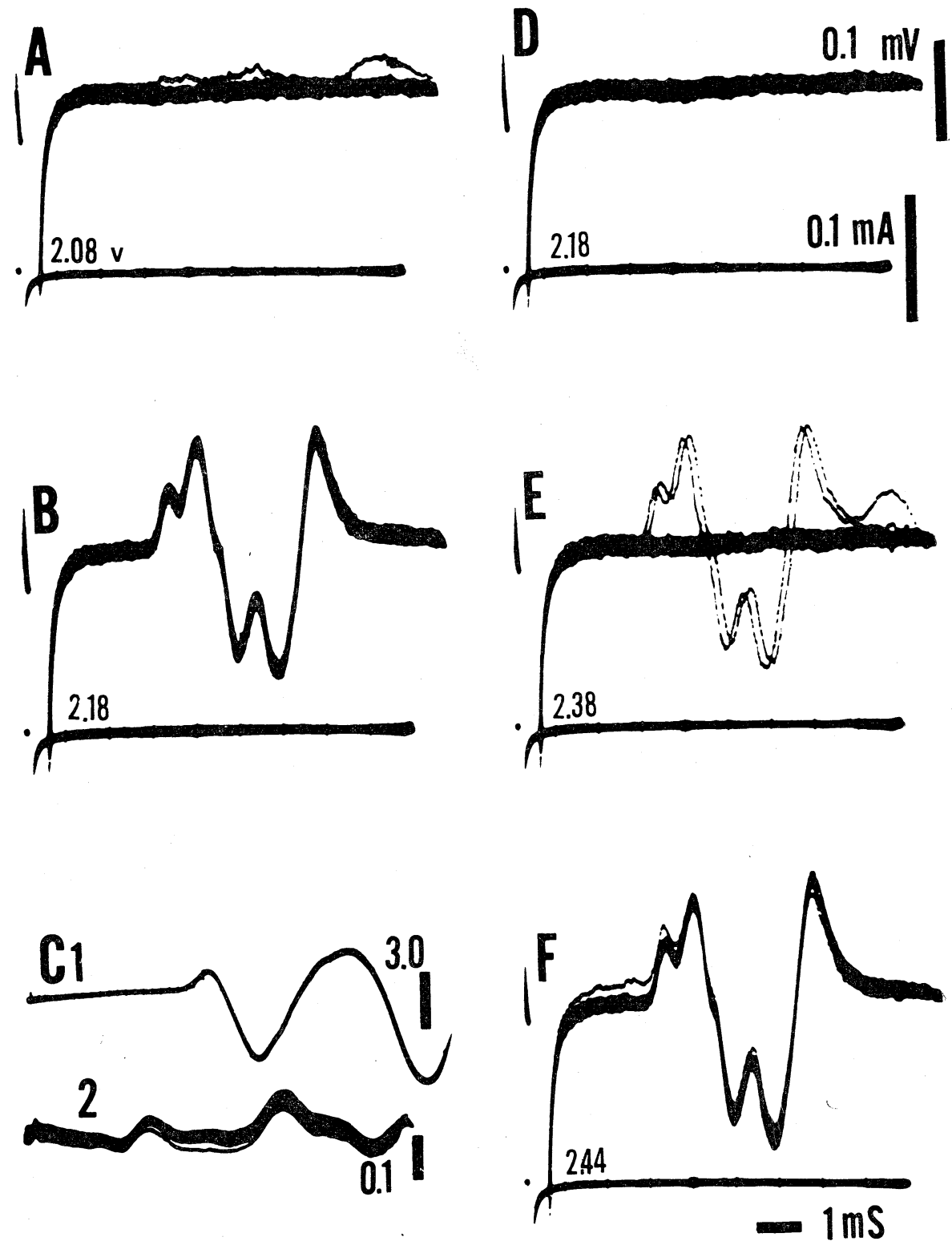

FIG. 3. Threshold increase of a motor neuron which innervates a single ankle extensor motor unit during a transition from slow wave (A and B) to activated sleep $(\mathrm{D}, \mathrm{E}$ and $\mathrm{F})$. Stimulus intensity of the cord is illustrated in the number at bottom left in each figure. Latency of the motor unit was $2.80 \mathrm{msec}$. C1: mass EMG response recorded through the same electrode as used for the unit recording at the same position within the muscle after the activated sleep episode. Sciatic nerve was stimulated supramaximally at a point where the hamstring nerve gave off (latency $1.65 \mathrm{msec}$ ). C2 : antidromic focal potential of the motor neuron evoked by the supramaximal sciatic nerve stimulation, similar stimulus as $\mathrm{C} 1$ but recorded 2 days after the experiment... Sweep speed for $\mathrm{C} 1$ and $\mathrm{C} 2$ is two times faster than the indicated calibration. 
brackets show the F. I.'s for respective trials. In the right half of the polygraph, the tonic neck EMG activity became almost silent, EEG showed low voltage fast wave pattern and eyes began to move around; thus the activated sleep developed. During the activated sleep even the shock 14-16\% higher than the control threshold during the slow wave sleep failed to evoke the unit responses $(\mathrm{L}, \mathrm{Q})$.

FIG. 3 illustrates another example of the threshold increase of a motor unit which belongs to the ankle extensor (latency from the cord stimulus, $2.80 \mathrm{msec}$ ). During the slow wave state, the response was not evoked in A $(2.08 \mathrm{~V})$ and was always evoked in $\mathrm{B}$ at slightly high intensity $(2.18 \mathrm{~V})$. Thus, the calculated threshold intensity is $2.13 \mathrm{~V}$. Responses in $\mathrm{D}, \mathrm{E}$, and $\mathrm{F}$ were

TABLE 1.

Summary of 15 motor units whereby threshold increase during activated sleep were observed. Parentheses of (3) represent latency of the EMG recorded by the electrodes picking up the unit response and latency of antidromic negative response of the motor neuron by the stimulation of the same peripheral nerve.

\begin{tabular}{|c|c|c|c|c|c|}
\hline No. of $\stackrel{(1)}{\text { motor unit }}$ & $\begin{array}{l}(2) \\
\text { Unit } \\
\text { latency }\end{array}$ & $\begin{array}{c}(3) \\
\text { Mass EMG } \\
\text { latency } \\
\text { from VR }\end{array}$ & $\begin{array}{l}(4) \\
\text { Difference } \\
(2)-(3)\end{array}$ & $\begin{array}{c}(5) \\
\text { Threshold } \\
\text { at slow } \\
\text { wave sleep }\end{array}$ & $\begin{array}{c}(6) \\
\text { Threshold } \\
\text { increase at } \\
\text { activated sleep }\end{array}$ \\
\hline \multicolumn{6}{|l|}{ (ankle extensor) } \\
\hline 1 & $3.0 \mathrm{msec}$ & $2.6 \mathrm{msec}$ & $0.4 \mathrm{msec}$ & $6.1 \mathrm{~V}$ & $33 \%$ \\
\hline 2 & 2.8 & 2.7 & 0.1 & 4.6 & 4 \\
\hline 3 & 2.6 & 2.4 & 0.2 & 2.8 & 18 \\
\hline 4 & 2.6 & 2.4 & 0.2 & 3.2 & 11 \\
\hline 5 & 2.8 & $(1.0+1.6)$ & 0.2 & 2.1 & 10 \\
\hline 6 & 2.9 & $(1.0+1.7)$ & 0.2 & 2.1 & 5 \\
\hline 7 & $\begin{array}{l}2.7 \\
(2.77)\end{array}$ & $\begin{array}{l}2.5 \\
(2.53)\end{array}$ & $\begin{array}{l}0.2 \\
(0.21)\end{array}$ & $\begin{array}{l}1.9 \\
(3.25)\end{array}$ & $\begin{array}{c}6 \\
(12.4=\mathrm{m})\end{array}$ \\
\hline \multicolumn{6}{|l|}{ (ankle flexor) } \\
\hline 8 & 3.0 & 2.7 & 0.3 & 2.7 & 11 \\
\hline 9 & 2.8 & 2.7 & 0.1 & 3.2 & 10 \\
\hline 10 & 2.7 & 2.7 & 0 & 2.2 & 12 \\
\hline 11 & 2.7 & 2.7 & 0 & 2.5 & 6 \\
\hline 12 & $\begin{array}{c}3.1 \\
(2.86)\end{array}$ & $\begin{array}{l}(1.0+1.8) \\
(2.72)\end{array}$ & $\begin{array}{l}0.3 \\
(0.14)\end{array}$ & $\begin{array}{l}3.3 \\
(2.78)\end{array}$ & $\begin{array}{l}17 \\
(11.2=\mathrm{m})\end{array}$ \\
\hline $\begin{array}{l}\text { (knee flexor-Biceps } \\
\text { femoris) }\end{array}$ & & & & & \\
\hline $\begin{array}{c}13 \\
\text { (knee extensor- } \\
\text { Quadriceps femoris) }\end{array}$ & 2.5 & 2.2 & 0.3 . & 8.1 & 14 \\
\hline 14 & 1.6 & 1.6 & 0 & 3.5 & 40 \\
\hline 15 & $\begin{array}{c}1.8 \\
(1.7)\end{array}$ & $\begin{array}{c}1.6 \\
(1.6)\end{array}$ & $\begin{array}{c}0.2 \\
(0.1)\end{array}$ & $\begin{array}{c}3.9 \\
(3.7)\end{array}$ & $\begin{array}{l}22 \\
(31=m)\end{array}$ \\
\hline
\end{tabular}




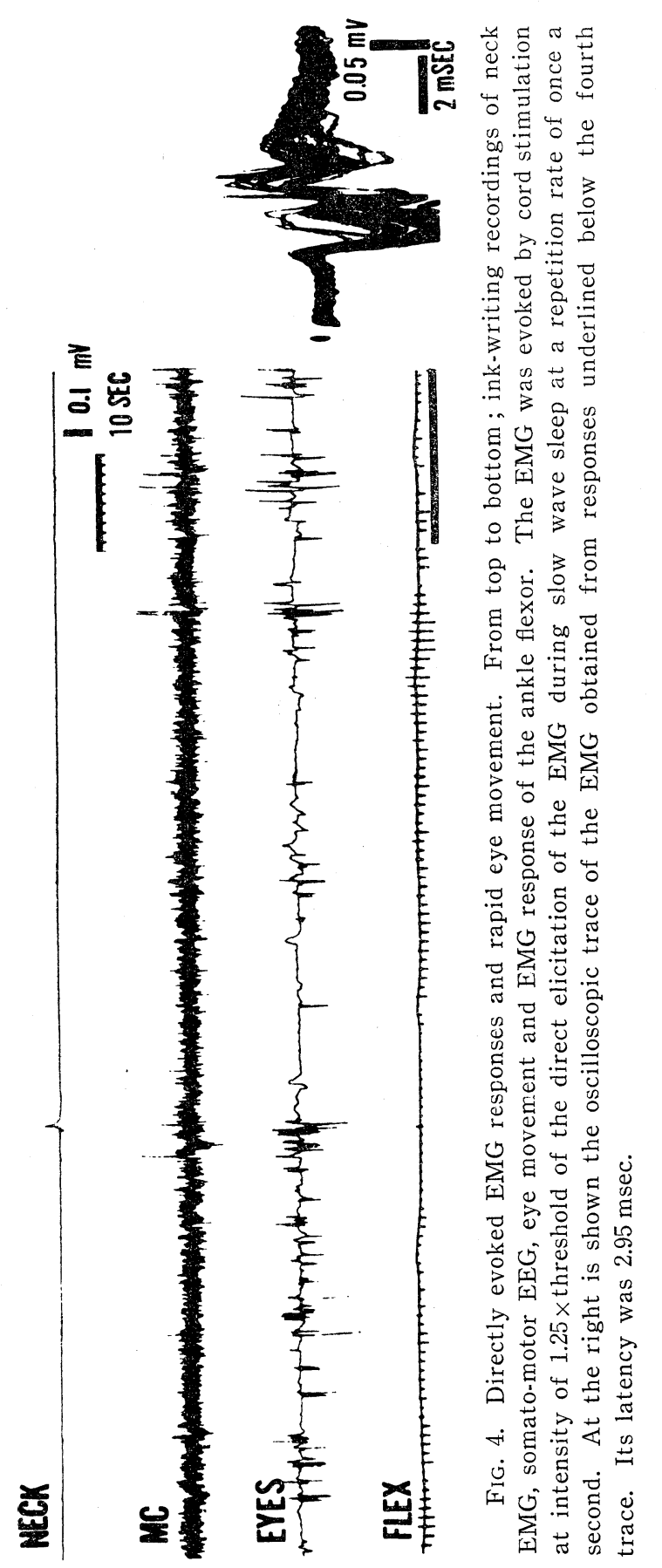


recorded during the activated sleep state. In $\mathrm{D}$, the same intensity as in $\mathrm{B}$ did not evoke the response. In $\mathrm{E}$ at slightly higher intensity $(2.38 \mathrm{~V})$, the unit responded to two of ten shocks. In two responses slight difference of the latency is noted $(0.2 \mathrm{msec})$. The response is always evoked in $\mathrm{F}$ at higher intensity $(2.44 \mathrm{~V})$.

TABLE 1 summarizes the data of 15 motor units.

The average threshold increase during activated sleep was about $15 \%$. No units were found which showed the threshold decrease during the activated sleep. When animals were awakened from the activated sleep, the threshold became higher or lower, depending probably on flexion or extension postures of the limb. When the animal returned to the slow wave sleep, the threshold returned to the value within the range of $15 \%$ of the preceding control (8 units). In 2 units were observed two successive episodes of the activated sleep during which the threshold increases were of similar order.

It has been reported that the monosynaptic reflex was transiently depressed during the rapid eye movement ${ }^{7,8}$. However, consistant threshold increase or decrease which closely associated with the rapid eye movement were not found in this study (FIG. 4).

\section{DISCUSSION}

During the activated sleep compared to the slow wave sleep, the lumbar motor neuron was less excitable in both flexors and extensors, as far as tested by the threshold change of the single motor unit evoked by the direct excitation of the motor neuron.

According to AsTÖM and PORTER, by the local stimulation of the lumber motoneuron pool in the cat, the axonal part of the spinal motor neuron was more easily excited than the soma or dendrites ${ }^{1,15}$. On the contrary, LORENTE DE Nó interpreted that in rabbit abducens the motor neuron soma had a lower threshold than the axon. In view of LORENTE DE Nó's data, AsTRÖM interpreted his results as that the soma was probably destroyed by the penetration of electrode. In this paper it was imposible to infer which part of the post-synaptic structures were excited by the cord stimulation. However, the threshold increase during the activated sleep appears to reflect, more or less, the hyperpolarization of the motor neuron membrane. Probably it is caused by the IPSP2,4) or subsidence of the EPSP.

As one factor of the latter case the presynaptic inhibition may be nominated. There is evidence that within the lateral geniculate body the optic tract fibers are depolarized during the activated sleep, indicating the presynaptic inhibitory influences thereupon to reduce the incoming volleys ${ }^{9}$.

However, evidence of the depolarization of primary afferent terminals in the spinal cord could not be available during the activated sleep ${ }^{16}$. Appli- 
cation of sufficient picrotoxin which would block the presynaptic inhibition in the monosynaptic pathway did not block the MSR depression in the activated sleep ${ }^{16)}$.

Therefore, presynaptic inhibitory mechanism appears as not involved to depressed the monosynaptic pathway during activated sleep.

\section{SUMMARY}

Excitability of the single motor neuron was tested by stimulating directly the lumbar cord in unrestrained and unanesthetized cats, and was compared between sleeps with slow wave and spindle burst in EEG (slow wave sleep) and sleep with low voltage fast wave in EEG (activated sleep). During the latter, the threshold to elicit the single motor unit by the direct excitation of the motor neuron increased in both hind-limb flexors and extensors.

We are grateful to Professor T. Tokizane for his encouragement and to Miss. T. SATO for histological preparations.

\section{REFERENCES}

1) Aström, K.E. On the functional organization of the motoneurons in the spinal cord. Acta physiol scand., 16 : Suppl. 55, 1-67, 1948.

2) Eccles, J.C. The Physiology of Synapses. Berlin, Springer, 1964.

3) Eccles, J.C., Magni, F. And Willis, W.D. Depolarization of Group I afferent fibers from muscle. J. Physiol., 160: 62-93, 1962.

4) Fukami, Y., Furukawa, T. And Asada, Y. Excitability changes of the Mauthner cell during collateral inhibition. J. gen. Physiol. $48: 581-600,1965$.

5) Gassel, M. M., Marchiafava, P. L. and Pompeiano, O. Tonic and phasic inhibition of spinal reflexes during deep, desynchronized sleep in unrestrained cats. Arch. ital. Biol., 102: 471-499, 1964.

6) Gassel, M. M., Marchiafava, P. L. and Pompeiano, O. Phasic changes in muscular activity during desynchronized sleep in unrestrained cats. An analysis of the pattern and organization of myoclonic twitches. Arch. ital. Biol., 102: 449470, 1964.

7) Giaquinto, S., Pompeiano, O. And Somogyi, I. Supraspinal modulation of heteronymous monosynaptic and of polysynaptic reflexes during natural sleep and wakefulness. Arch. ital. Biol., 102: 245-281, 1964.

8) Giaquinto, S., Pompeiano, O. And Somogyi, I. Descending inhibitory influences on spinal reflexes during natural sleep. Arch. ital. Biol., 102: 282-307, 1964.

9) Iwama, K. ANd SAKAKuRA, H. Impulse transmission in cat lateral geniculate and so-called deep sleep wave. Proc. Japan Acad., 41 : 499-502, 1965.

10) Kubota, K., Imamura, Y. and Nimi, Y. Monosynaptic reflex and natural sleep in the cat. J. Neurophysiol., $28: 125-138,1965$.

11) Kubota, K. and Kidokoro, Y. Excitability change of. the motoneuron during activated sleep in the chronic cat. Abstracts of papers presented at XXIII International Congress of Physiological Sciences. No. 1079. 1965.

12) Lorente de Nó, R. The synaptic delay of the motoneurones. Amer. J. Physiol., 111: 272-282, 1935. 
13) Lorente de Nó, R. The electrical excitability of the motoneurones. J. cell. comp. Physiol., 7: 47-71, 1935.

14) LORENTE DE Nó, R. Limits of variation of the synaptic delay of motoneurons. J. Neurophysiol., 1: 187-194, 1938.

15) Porter, R. Focal stimulation of hypoglossal neurones in the cat. J. Physiol., 169 : 630-640, 1963.

16) Renshaw, B. Activity in the simplest spinal reflex pathways. J. Neurophysiol., 3: 373-387, 1940.

17) Tokizane, T. Studies on the paradoxical phase of sleep in the cat. In: Progress in Brain Research Vol-21 Correlative neurosciences edited by T. Tokizane and J. P. Schadé. Elsevier, Amsterdam, In press. 